(199)

\title{
Quality of Municipal Solid Waste Compost Produced in Sri Lanka
}

\author{
Wijerathne P.W.D.S.S. ${ }^{*}$, Senanayake D.M.N. ${ }^{1}$, Gamage S. ${ }^{2}$ and Jayakody A.N. ${ }^{3}$ \\ ${ }^{I}$ Central Environmental Authority, Sri Lanka \\ ${ }^{2}$ LIRNEasia, Sri Lanka \\ ${ }^{3}$ Faculty of Agriculture, University of Peradeniya, Sri Lanka \\ *sanjeewa7cea@gmail.com
}

\begin{abstract}
Rapid urbanization has made solid waste management a serious problem for local authorities in Sri Lanka. The compost production with Municipal Solid Waste (MSW) and good quality assurance of compost produced by such is crucial in utilizing these problematic wastes as an agriculturally important product. This study was focused on evaluating the overall quality of Municipal Solid Waste Compost (MSWC) in Sri Lanka. Primary and secondary data of compost physicochemical and biological characters covering 45 composting sites representing $88 \%$ of functioning Pilisaru composting sites of SL were used for the study. A large set of secondary data on MSWC quality parameters were collected from well reputed government laboratories with the approval of the Central Environmental Authority (CEA). Inadequate data were analyzed. Box plots were developed using data on color, moisture, odor, sand content, particle size, $\mathrm{PH}$, conductivity, organic carbon, $\mathrm{C}: \mathrm{N}$ ratio, total nitrogen, Phosphorus, Potassium, Magnesium, Calcium, Arsenic, Cadmium, Chromium, Copper, Lead, Mercury, Nickel, Zinc, Fecal coliform and Salmonella in MSWC samples. Central tendency, data distribution and deviations of each parameter were identified after eliminating outliers. The conformity percentage to Sri Lankan Standards (SLS) and Bureau of Indian Standards (BIS) were calculated. The heavy metal contents were compared with Portugal, France and Italy standards for MSWC in addition to SLS and BIS. Normal probability plots of the residual were designed in order to identify the data distribution pattern. Spatial variability of data in each individual parameter was analyzed in district basis. Mean and median value of moisture content, sand content, $\mathrm{MgO}, \mathrm{Hg}$ content and fecal coli form was not conformant with SLS and BIS. Although the mean value of particle size conformant with BIS it has exceeded the levels in SLS. Cd, Cu, Zn and Ni contents showed $100 \%$ conformity with SLS, BIS, France, Italy and Portugal standards. $\mathrm{Cr}$ and $\mathrm{Pb}$ contents showed more than $90 \%$ conformity to all the standards. Colour, odour, $\mathrm{pH}$, organic carbon, total $\mathrm{N}, \mathrm{Ca}, \mathrm{Cd}, \mathrm{Cr}, \mathrm{Cu}, \mathrm{Pb}, \mathrm{Ni}, \mathrm{Zn}$ and salmonella resulted in more than $75 \%$ conformity to SLS. Sand content is the most deviated parameter from SLS. Significant special variability was reported for particular districts with regard to sand content, $\mathrm{pH}$, total $\mathrm{N}, \mathrm{P}_{2} \mathrm{O}_{5}$ and $\mathrm{K}_{2} \mathrm{O}$. Thus, MSWC quality in SL could be improved via giving the emphasis on the parameters which are not conformant with the standards.
\end{abstract}

Keywords: Municipal Solid Waste Compost (MSWC), Sri Lankan Standard (SLS), Bureau of Indian Standard (BIS)

Proceedings of the International Forestry and Environment Symposium 2016, Department of Forestry and Environmental Science, University of Sri Jayewardenepura, Sri Lanka. 